\title{
Quality Improvement
}

\section{Informing Strategy to Ensure Detection: Perceptions of Coronavirus Testing in a Southeastern U.S. Urban Homeless Population}

Colleen Bell, MD, FACHE, FAPA, ${ }^{1,2}$ Theodore Bosi, MD, ${ }^{2}$ Barbara L. Gracious, MD ${ }^{2,3,4}$

\section{Abstract}

\section{Introduction}

Attitudes of those in the homeless population toward testing, particularly during a pandemic, are critical to understand, so that they and their communities may be safely triaged and protected. Homeless persons are more likely to be exposed during viral epidemics, and have greater vulnerability for more severe viral illness, due to greater medical comorbidities. The literature reflects a dearth of published papers describing the perceptions, interest, and motivations of homeless people to seek or receive viral testing, despite their status as a high-risk population.

\section{Methods}

A quality improvement project consisting of a cross-sectional survey took place at 8 SARS-CoV-2 infection testing sites (local shelters and drop-in sites) within Duval County, Jacksonville, FL.

\section{Results}

The vast majority of homeless individuals approached for testing completed demographic data and a checklist of beliefs and attitudes about testing $(\mathrm{N}=764)$ and underwent COVID-19 nasopharyngeal swab testing ( $n=679)$. Mean age was $48 ; 66 \%$ were male, and the predominant race was Black (51\%) with $89 \%$ of non-Hispanic ethnicity. Of the total participants, $59.2 \%$ wanted testing and $4.6 \%$ declined testing. Attitudes toward testing varied by site and by wanting vs. not wanting to be tested. Top reasons in those wanting testing included curiosity; a belief that faith would protect them from the virus; and having shelter encouragement to be tested. Top attitudes among those not wanting to be tested were: shelter encouraged me; curiosity; and receiving a gift card. For the total group of subjects, being offered a $\$ 10$ gift card did not affect their desire to be tested. Those who were not faith-influenced were less likely to want testing.

\section{Conclusion}

Findings from selected literature and this quality improvement study support the use of a variety of strategies to encourage participation in testing events with large numbers of homeless individuals, including education, gift cards, shelter staff encouragement, involvement of local faith leaders and more broad support by the community. An additional qualitative study would complement these findings, as populations appear to differ in beliefs and attitudes depending on their location and other demographics. Motivational strategies to influence testing rates can be fine-tuned if beliefs, perceptions and attitudes are better understood.

\section{Keywords}

SARS-CoV-2; COVID-19; coronavirus infections; coronavirus infections/prevention \& control; pandemics; homeless persons; risk factors; infectious disease transmission; quality improvement; patient education as topic
Author affiliations are listed at the end of this article.

Correspondence to: Colleen Bell, MD, FACHE,

\section{FAPA}

Sulzbacher Center

$611 \mathrm{E}$. Adams St.

Jacksonville, FL 32202 (colleenbell@sulzbacherjax. org)

\section{HCA is Healthcare}

\section{www.hcahealthcarejournal.com}

(C) 2020 HCA Physician Services, Inc. d/b/a Emerald Medical Education
HCA Healthcare Journal of Medicine 


\section{Introduction}

The current SARS-CoV-2 pandemic has raised concerns for the homeless in both social service agencies and medical communities, as the homeless are more likely to be both victims and vectors of disease spread. Homeless individvals historically have greater exposure to viral epidemics (influenza as a prime example), as well as greater vulnerability for more severe viral illness, due in part to comorbidities such as pre-existing respiratory and cardiac disease, drug use and diabetes. ${ }^{1-6}$ Contributory environmental risks include inadequate sanitation, lack of access to healthcare services, crowded living conditions (e.g., shelters, hotels and rooming houses), interactions with legal and penal systems and general lack of personal protective equipment (PPE). ${ }^{7}$ Baggett et al. states that "the high number of asymptomatic SARSCoV-2 infections and the potential for rapid spread in congregate settings support the need for proactive, universal COVID-19 testing strategies" in homeless populations. ${ }^{3}$

Testing for both active and recent SARS-CoV-2 infection, via reverse transcription-polymerase chain reaction or antibody detection, are key components of general community prevention. Testing in 4 major U.S. cities between late March and mid-April 2020 found that up to $66 \%$ of San Francisco homeless shelter residents and $16 \%$ of homeless shelter staff were positive for SARS-CoV-2. ${ }^{8}$ Community incidence outside of homeless shelters was highest in Boston, at $14.4 \%$, as a comparison. After a rapid outbreak among 3 homeless service sites in King County, Washington State, the Centers for Disease Control stated that rapid interventions, including testing and isolation to identify cases and minimize transmission, were necessary. ${ }^{9}$ A pilot study of COVID-19 testing and support to reduce outbreak risk in Hamilton, Ontario (Canada) used strategies of shelter facility restructuring, daily symptom screening and rapid testing via nasopharyngeal swab (NPS) for those endorsing viral symptoms. These strategies resulted in isolation precautions, but no denominator was given as to whether any residents refused testing or isolation, or what they understood about the virus and how to manage symptoms. ${ }^{10}$

Kumar Kar et al. note that homeless mentally ill people have a lack of health awareness and poor help-seeking behaviors due to marginalization." Homeless populations receive preventive screening or test results less often, including for HIV and hepatitis (as well as for cervical and breast cancer in homeless women), despite greater risk. 3,6,10,12-14 Public health officials and homeless service providers emphasize that homeless persons need to follow virus precautions while maintaining usual ongoing health care due to their high risk for medical and psychiatric decompensation. ${ }^{7}$ To prevent viral outbreaks in homeless communities, work has included: 1) enhanced communication strategies, 2) infection control actions including isolation quarantine methods, 3 ) resource allocation, to mitigate against illness exposure and environmental immune stresses (such as lack of sleep and nutrition) and 4) planning for future outbreaks. ${ }^{15,16}$ Spirituality is an additional important factor to consider, as a study by Tsai and Rosenheck concluded that religious faith in chronically homeless adults may influence clinical and psychosocial outcomes. ${ }^{17}$ The homeless must have basic knowledge and ideally connections with case managers, outreach staff and faith leaders to partner together in mitigation, infection control and ongoing health maintenance.

It is, therefore, critical to know the attitudes of homeless individuals about COVID-19 testing and their rates of accepting testing, so that the homeless and their communities may be safely triaged for illness, quarantined if exposed or tested and if positive, isolated, protected and appropriately treated. To better understand the testing attitudes, perceptions, and motivations in the Duval County, Jacksonville, FL homeless population, Sulzbacher Center, a Federally Qualified Healthcare Center, undertook a quality improvement (QI) project. The QI project was performed simultaneously to a clinical testing outreach and a collaborative research study with a university medical center to learn more about current health status and the comorbid health conditions in the Duval County homeless population. The QI project consisted of a questionnaire given before and after giving and reviewing a Centers for Disease Control (CDC) fact sheet on COVID-19 and/ or NPS testing. The information learned from this project was to immediately inform feasible ways to increase testing and compliance with treatment and infection control strategies in 
Figure 1. Bell Homeless Perceptions of Covid-19 Testing Checklist

\section{Please place a check mark next to any of the following that may apply to your beliefs about coronavirus testing:}

I want the testing, I believe it will help me and others

I don't really think I need it but I will get it done because:

My family and/or friends have said I should

My healthcare team has said I should

I'm curious about the test and/or the results

l'll get a gift card or other incentive

Other:

I don't really think I need the testing due to the following (check all that apply)

I am afraid it may hurt

I am already isolated from society

My faith will protect me from the virus

I'm worried about what will be done with my information

I don't really want to know

I don't really care - there are other things that worry me more

Other:

predicted future waves or new pandemics.

\section{Methods}

The Sulzbacher QI Committee approved this project in consultation with Dr. Michael Flynn, HCA South Atlantic Division Director of Research. Nasopharyngeal swabs for SARS-CoV-2 were donated to Sulzbacher Center by Quest Laboratories as part of a clinical initiative to learn the point prevalence of COVID-19 in the Duval County, Jacksonville, FL homeless population. The NPS testing was done in partnership with other local homeless shelters and drop-in centers, and was available to all who wanted it, including shelter residents and staff. NPS testing was performed on May 1, 4, 5, 6 and 7, 2020. The City of Jacksonville provided funds for $\$ 10$ grocery gift cards to encourage participation.

To coordinate the testing, Sulzbacher Center teamed with Changing Homelessness (a Housing and Urban Development (HUD) grant-funded social service umbrella agency dedicated to advocacy, training, education and communication linkage) and the University of Florida Health-Jacksonville (UF Health; an academic health center located in areas of need in Duval County). The Sulzbacher Center and UF Health performed testing and data collection. Both Sulzbacher and UF Health used their mobile medical bus for the outreach. UF Health also conducted a simultaneous research project collecting clinical data about current health status and medical comorbidities, approved by their Institutional Review Board. A total of 8 testing sites, local shelters and drop-in sites within Duval County, Jacksonville, FL were included: Sulzbacher Center Downtown, Sulzbacher Village, Salvation Army Downtown, City Rescue Mission-McDuff Avenue, City Rescue Mission-Downtown, Trinity/Clara White Missions, Urban Rest Stop-Church Street and Urban Rest Stop-Downtown.

The Bell Homeless Perceptions of COVID-19 Checklist (Figure 1) was given to the shelters and drop-in centers ahead of the testing dates. Those aged 18 years or older, who were homeless residents of the shelters, walk-in homeless or homeless center staff members were asked to participate. Staff members gave a paper form of the Bell Checklist to those who were interested in being tested for COVID-19 before the NPS testing. The form also included non-identifiable demographic information and reasons why they may be agreeing to testing. Clinical staff then reviewed key points of the CDC education form about the COVID virus (see Appendix A) or gave out the CDC education form about the COVID virus. Those who were not considered a staff member were provided with a $\$ 10$ gift card at the end of the data collection.

Testing and survey collections were performed by staff from Sulzbacher Center, Changing Homelessness, UF Health (including paid, previously furloughed, physical therapists) and Or- 
ange Park Medical Center Psychiatry Program residents. Demographic data was collected so testing results could be reported to the individual; also, so they could be notified of testing results by the Duval County Department of Health (as required by law if positive) and the individual's insurance company billed for the analysis, if applicable. The QI component was not linked to any personal health information $(\mathrm{PHI})$. Each individual was given a unique identifier. Paper data was entered without PHI into an Excel spreadsheet by Dr. Bell. Hard copies of the data were kept in a locked file cabinet in a locked office at Sulzbacher Center. To tabulate and understand the results, hypotheses, percentage data, crosstab and chi-square tests were completed using IBM SPSS Statistics $24 .^{18}$ Data that was unknown was left as missing but if a checklist form was completed before or after testing, or without testing, the individual was counted as an active participant.

\section{Results}

\section{Demographics}

Demographic data are presented in Table 1 by total group and by site. Homeless participants $(N=764)$ in this $Q 1$ project had a mean age of 48 years with the bulk of participants over age 50 (46.9\%). The mean age varied based on location, with the lowest mean age of 39.5 years at Sulzbacher Village, which houses families, and the highest being at CRM McDuff (52.4 years). The majority of participants did not have insurance $(66.9 \%)$, which again varied based on location (the Salvation Army showed the highest insured rate at $51 \%$ ). The majority of participants were male (66.0\%) with the highest percentage of females being at the Sulzbacher Village (50.0\%), and no females being at Sulzbacher Downtown (a men-only campus).

Black/African American was the predominant race identified (51\%) with Trinity/Clara White showing the highest percentage of Black/African Americans (59\%). Non-Hispanic was the most common ethnicity (89\%) with the highest percentage (96\%) of non-Hispanic participants tested at the Urban Rest Stop Downtown.

(Table 1) Ethnicity is reported separate from race as per 1997 U.S. Office of Management and Budget Revisions to the Standards for the Classification of Federal Data on Race and Ethnicity (https://obamawhitehouse.archives.gov/ omb/fedreg 1997standards).

\section{Test Acceptance}

( $N=679 ; 88.9 \%$ of the 764 who completed a Bell Checklist)

\section{Attitudes toward testing}

Pre-NPS test attitudes demonstrated that the majority (59.2\%) wanted to be tested; $24.7 \%$ did not answer; $10.1 \%$ did not think they needed to be tested but agreed to it, and $4.6 \%$ did not want to be tested and declined testing, with $0.3 \%$ tested but declining to answer the Bell Checklist. Post-NPS testing, 53.1\% wanted testing, with $20.3 \%$ stating they did not want it (though still got it) and $19.6 \%$ did not answer (unknown). Sulzbacher Downtown had the most $(90.5 \%)$ participants wanting the NPS test on the Bell Checklist pre-NPS test, which dropped to $53.6 \%$ post-NPS testing (Table 2 ).

The top reasons all participants as a group wanted to get the NPS testing (beyond believing it would help them or others, which was endorsed when stating a desire to be tested) (Table 2) were: 1) "I'm curious about the test and/or the results" (47.8\%), 2) "The shelter encouraged me to go" (37.6\%), 3) "My faith will protect me from the virus" (31.3\%), 4) "I'll get a gift card" (24.2\%), 5) "My family and/or friends have said I should" (14.1\%), and 6) "My healthcare team said I should" (8.1\%). Reasons to not be tested included: 1) "I am already isolated from society" (20.3\%), 2) "I am afraid it may hurt" (14.8\%), 3) "I'm worried about what will be done with my information" (3.3\%), 4) "I don't really care - there are other things that worry me more" (2.9\%), and 5) "I don't really want to know" (0.4\%). Of note, at the Urban Rest Stop Downtown location, the number one reason to be tested was the gift card $(63.1 \%)$, while at CRM McDuff, Trinity/Clara White and CRM State the number one reason was that the "The shelter encouraged me to go" $(73.7 \%$, $44.8 \%$ and $58.9 \%$, vs. $10.5 \%, 12.7 \%$, and $18.5 \%$ for the gift card, respectively).

For those who wanted testing, the most endorsed attitudes were: 1) "I'm curious about the test and/or the results"; 2) "My faith will protect me from the virus"; and 3) "The shelter encouraged me to go." (Table 3) For those who didn't want testing, the top attitudes were: 1) "The shelter encouraged me to go"; 2) "I'm curious about the test and/or the results"; and 3) "I'll get a gift card." All the attitude respons- 


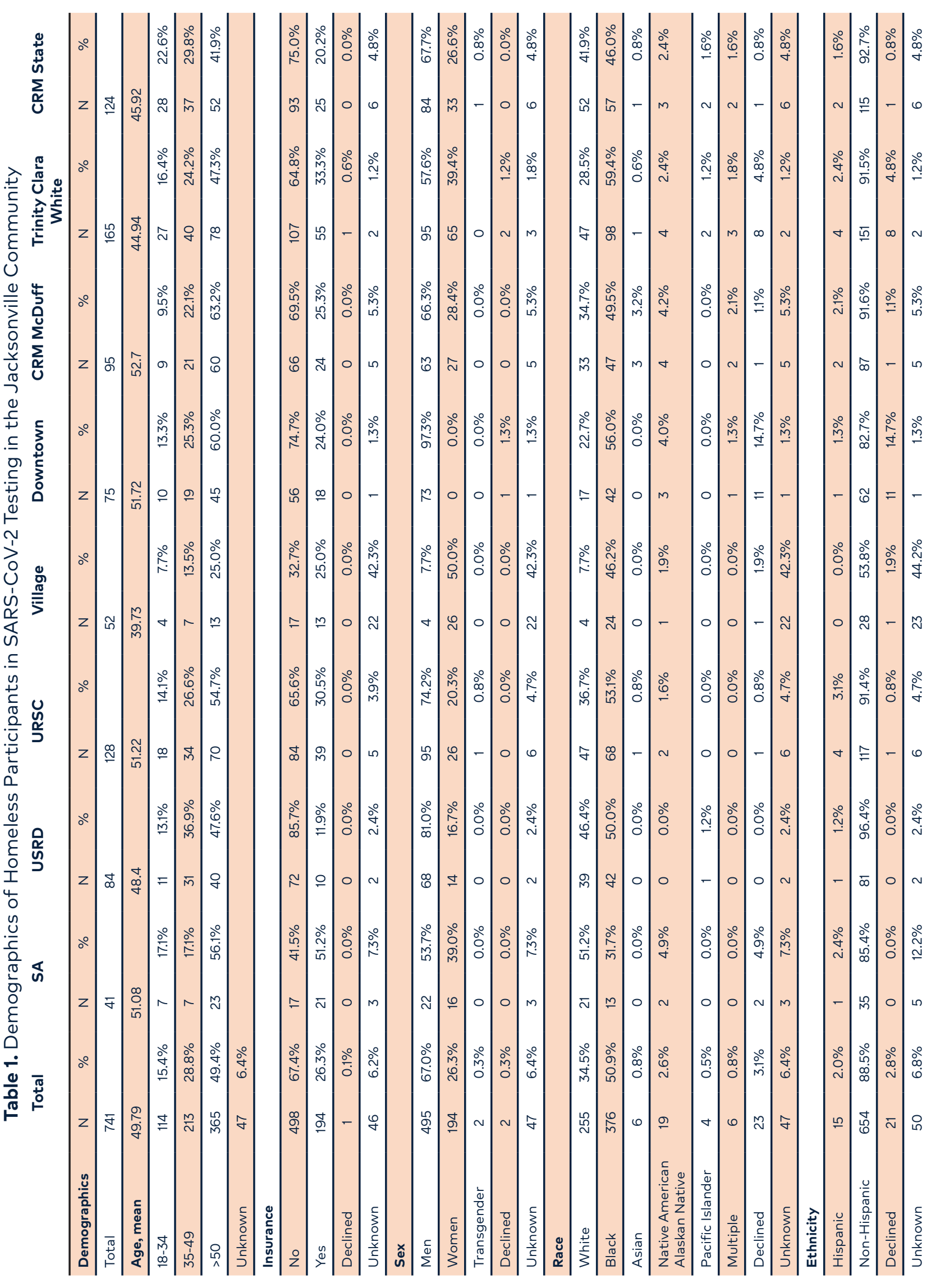




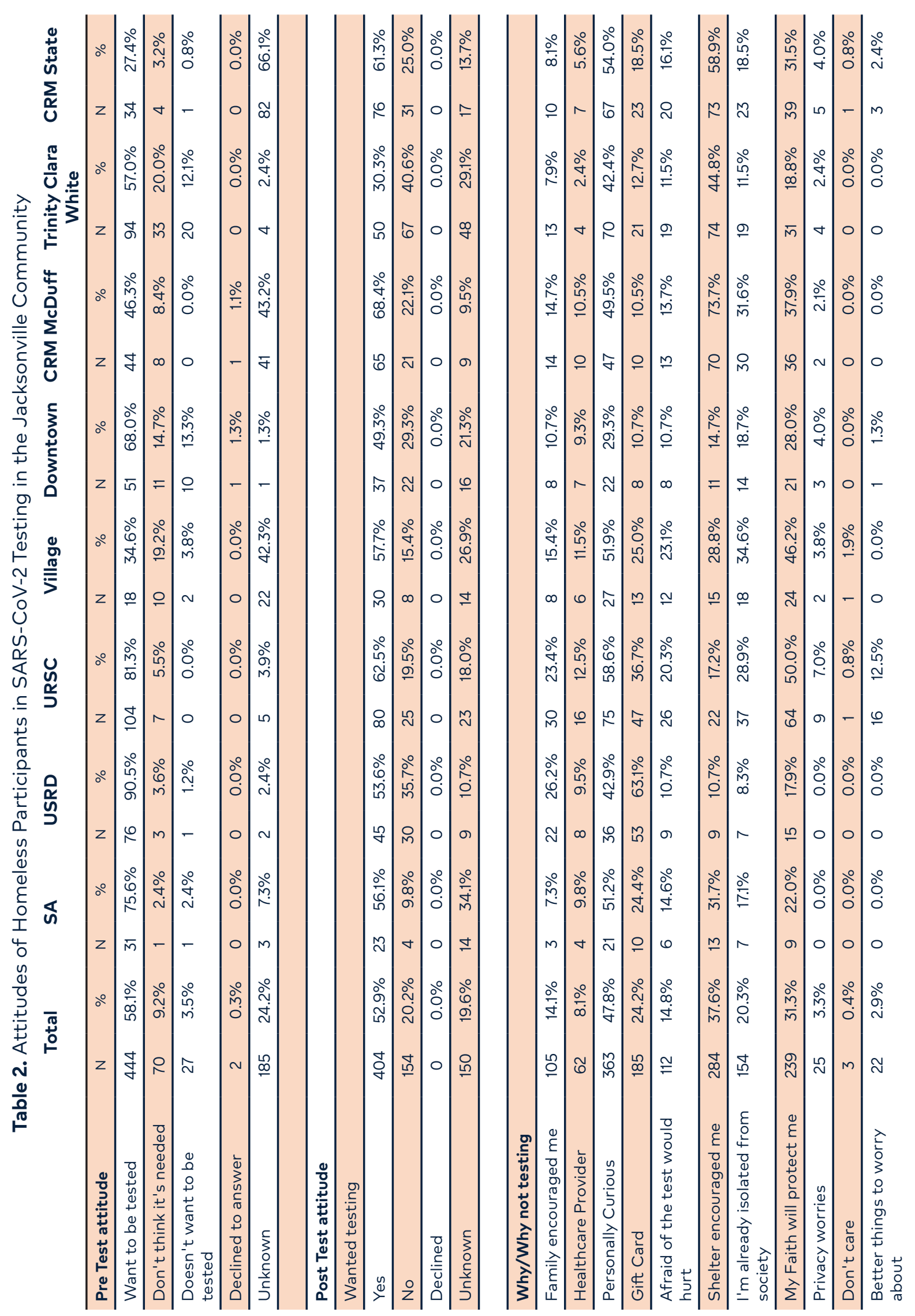


Bell et al. (2020) 1:COVID-19. https://doi.org/10.36518/2689-0216.1178

Table 3. Population Attitudes Towards SARS-CoV-2 Community Testing in Jacksonville

Wanted testing?

\begin{tabular}{|c|c|c|c|c|}
\hline \multirow[b]{2}{*}{ Attitude } & \multicolumn{2}{|c|}{ NO } & \multicolumn{2}{|c|}{ YES } \\
\hline & $\mathbf{N}$ & $\%$ & $\mathbf{N}$ & $\%$ \\
\hline Family/friends said I should & 25 & $23.4 \%$ & 82 & $76.6 \%$ \\
\hline Healthcare team said I should & 15 & $24.6 \%$ & 46 & $75.4 \%$ \\
\hline Curious about the test and/or the results & 80 & $22.1 \%$ & 282 & $77.9 \%$ \\
\hline Gift card or other incentive & 66 & $36.1 \%$ & 117 & $63.9 \%$ \\
\hline Afraid it would hurt & 22 & $19.5 \%$ & 91 & $80.5 \%$ \\
\hline Shelter encouraged me to go & 108 & $37.8 \%$ & 178 & $62.2 \%$ \\
\hline Already isolated from society & 44 & $29.1 \%$ & 107 & $70.9 \%$ \\
\hline Faith will protect me from the virus & 50 & $21.2 \%$ & 186 & $78.8 \%$ \\
\hline $\begin{array}{l}\text { Worried about what will be done with my } \\
\text { information }\end{array}$ & 9 & $36.0 \%$ & 16 & $64.0 \%$ \\
\hline Don't really want to know & 2 & $66.7 \%$ & 1 & $33.3 \%$ \\
\hline Don't really care, other things worry me more & 12 & $54.5 \%$ & 10 & $45.5 \%$ \\
\hline
\end{tabular}

es differed between those who wanted NPS testing compared to those who did not want the test, based on Pearson Chi-Square Tests (chi-square 130.467, df 11, sig. 0.000; Table 3). Further subanalysis teased apart individual differences in attitudes between the two groups. First, whether or not participants wanted the gift card did not influence their desire to get testing (chi-square 0.45, df 1, sig 0.5). Second, people who wanted testing were more likely to believe that faith would protect them from the virus (chi-square 28.558, df 1, sig. 0.000). People who were not faith-influenced were less likely to want testing.

\section{Discussion}

This quality improvement project was unique in that it examined perceptions, interest, and motivations of homeless people to seek or receive active viral testing during a pandemic. The Sulzbacher Center undertook this project with the aim not only to test clinically for SARS-CoV-2, but to understand the beliefs and perceptions about why homeless individuals agreed to be tested, with a client-centered, collaborative, quality improvement focus. Too often the homeless population is ignored or directed to comply with edicts. If their attitudes are considered, organizations that serve the homeless will be better informed to approach and partner with homeless individuals on major health crises, such as a pandemic, with true buy-in and informed consent.

The quality improvement study was conducted in Jacksonville, Florida, a state that did not expand Medicaid. It is not surprising therefore that the majority of individuals (66.9\%) in this study lacked insurance. Black/African American was the most common race identified in this homeless population, which nationally makes up 40 percent of the homeless population despite representing only 13 percent of the general population, due to factors such as poverty, rental housing discrimination, incarceration and lack of mental health treatment. ${ }^{19}$ The percentage of males and females in this study $(66.0 \%$ and $27.1 \%$, respectively) were in keeping with the annual point-in-time count data for Florida in 2019 (64.8\% male and $34.9 \%$ female).$^{19}$

Although the top reason for the total number of homeless persons to get the nasopharyngeal swab testing was curiosity, for those not wanting testing, the most common attitude was being encouraged by the shelter to go. Some attitudes varied by site, with some sites taking a more mandatory approach to testing (CRM McDuff, Trinity/Clara White and CRM State), 
resulting in a highest value of $73.7 \%$ of homeless endorsing shelter encouragementversus a low of $10.7 \%$ at the Urban Rest Stop-Downtown. Faith played an important role with the perceptions of the homeless clients, with close to one third (31.3\%) of all participants citing it as a factor in their approach to testing in the pandemic. Over $75 \%$ of those wanting testing felt faith would protect them. One individual asked a resident volunteer if the question on faith was "a trick question" and stated, "I believe in God but I also believe in science." Homeless individuals also changed their view of the testing at the Sulzbacher downtown site after the NPS, with $90 \%$ initially indicating they wanted testing declining to almost half after testing; anecdotal comments included: test discomfort, and invasion of privacy. The time of day the testing occurred may also have played a role in the post-testing decline and responses: often individuals do not stay at the shelter during the day, and the pre-NPS checklists were completed in the evening when more people were on campus. People who only considered testing in response to a paternalistic approach or a gift card are consistent with a pre-conventional moral development level (Kohlberg's Level 1), where they have an obedience and punishment or self-interest orientation. Those homeless who endorsed both faith and a desire to be tested may be more prosocially oriented toward 'the greater good', and may be representative of Kohlberg's post-conventional Level 3. Level 2 (conventional) are the individuals who are conforming to authority. ${ }^{20}$

\section{Limitations}

The number of homeless tested at the Sulzbacher Village was lower than expected, as well as least robust in data collection. Also of note, the mobile medical bus and internet were experiencing technical difficulties that day.

Other limitations of this project include realworld behaviors. Different shelter sites had variable approaches toward encouraging testing by staff; this may reflect the reality that some staff and sites have more paternalistic or authoritative attitudes rather than encouraging self-actualizing behavior, or may themselves may be fearful of COVID and its complications for themselves and their clients and understandably want their clients tested. Therefore, bias in attitudes of those completing testing may be present. The current study did not a priori characterize or analyze homeless shelter sites by the subgroups of populations served. Those in a rest stop may be considerably different than those in an overnight shelter. Those in the Sulzbacher Village were by definition more likely to be women. Additionally, the project did not include homeless adolescents. They are another important subgroup whose attitudes often differ from adults. The survey itself was brief and not psychometrically designed or tested for validity or reliability. It also lacked a full range of attitudes to inquire about, including more positive variables, potentially creating a bias in valence of response.

There is little literature with which to compare this project to. The majority of publications about beliefs, attitudes, and perceptions are toward the homeless, rather than of the homeless. The closest comparison is with an influenza mobile outreach immunization program for vulnerable populations in Melbourne, Australia. Although over half the group had at least one risk factor for severe influenza, $60 \%$ had not received an influenza vaccine the prior year, with most reporting that they were 'not worried about influenza' as their reason. Those who were pregnant listed a health care provider's recommendation as the most frequently given reason for why they desired immunization. ${ }^{21}$ These results for a potentially similar respiratory viral outbreak indicate that paternalism and cultural and educational variables affect health care literacy and promotion and alter perceptions of preventive care in vulnerable populations.

Findings from this quality improvement study support considering a variety of strategies to encourage participation in testing events with large numbers of homeless individuals. These include: education, gift cards, shelter staff encouragement (especially for retesting), local faith leader involvement and increased support from the community, to encourage self-isolation, when necessary, and to help the homeless meet self-care and basic needs. The best strategies may be specific to the shelter and their staff and clients, as some between-group differences are noted for site of participation. Future projects can ideally allow adequate planning time so that focus groups including 
homeless persons, shelter staff and health care workers from a variety of settings may together discuss survey items and how to best test strategies to promote compliance with pandemic recommendations for screening, prevention and treatment.

\section{Acknowledgements}

We thank UF Health for their assistance with testing and data collection, specifically Ann Marie-Knight, MHA. We thank Mary Pat Corrigan for testing, survey and informed consent collaboration. We thank the Orange Park Medical Center Psychiatry Residents David Ballack DO, Mohsin Raza MD, Sully Farooqui DO, Kourosh Mehrazar MD, Mohsin Zafar MD and Adnan Sharifi MD for data collection. We also thank Danielle Kocsis, MSc for statistical analysis assistance and study guidance.

\section{Conflicts of Interest}

Dr. Gracious reports personal fees from Novo Nordisk, outside the submitted work. Drs. Bell and Bosi declare they have no conflicts of interest.

The authors are employees of Orange Park Medical Center, a hospital affiliated with the journal's publisher.

This research was supported (in whole or in part) by HCA Healthcare and/or an HCA Healthcare affiliated entity. The views expressed in this publication represent those of the author(s) and do not necessarily represent the official views of HCA Healthcare or any of its affiliated entities.

\section{Author Affiliations}

1. Sulzbacher Center, Jacksonville, FL

2. GME Psychiatry Program, Orange Park Medical Center, Orange Park FL

3. Edward Via College of Medicine, Spartanburg, SC

4. Department of Psychiatry and Behavioral Health, The Ohio State University, Columbus, $\mathrm{OH}$

\section{References}

1. Snyder LD, Eisner MD. Obstructive lung disease among the urban homeless. Chest. 2004;125(5):1719-1725. https://doi.org/10.1378/ chest.125.5.1719
2. Baggett TP, Liauw SS, Hwang SW. Cardiovascular Disease and Homelessness. J Am Coll Cardiol. 2018;71(22):2585-2597. https://doi.org/10.1016/j. jacc.2018.02.077

3. Baggett TP, Racine MW, Lewis E, et al. Addressing COVID-19 Among People Experiencing Homelessness: Description, Adaptation, and Early Findings of a Multiagency Response in Boston. Public Health Rep. 2020;135(4):435-441. https://doi.org/10.1177/0033354920936227

4. Miyawaki A, Hasegawa K, Tsugawa Y. Lessons from Influenza Outbreaks for Potential Impact of COVID-19 Outbreak on Hospitalizations, Ventilator Use, and Mortality Among Homeless Persons in New York State. J Gen Intern Med. 2020;35(9):2781-2783. https://doi.org/10.1007/ s11606-020-05876-1

5. Homelessness and Racial Disparities. National Alliance to End Homelessness. https://endhomelessness.org/homelessness-in-america/ what-causes-homelessness/inequality/. Accessed August 17, 2020.

6. Powell J, Konadu Fokuo J, Anderson A, et al. Homeless shelter client and provider barriers and facilitators to implementing HCV testing, access, and linkage to care in the homeless population. Presented at: AASLD/EASL HCV Special Conference; February 6, 2019; Miami, FL. https:// www.natap.org/2019/AASLDEASL/AASLDEASL 15.htm

7. Tsai J, Wilson M. COVID-19: a potential public health problem for homeless populations. Lancet Public Health. 2020;5(4):e186-e187. https:// doi.org/10.1016/s2468-2667(20)30053-0

8. Mosites E, Parker EM, Clarke KEN, et al. Assessment of SARS-CoV-2 Infection Prevalence in Homeless Shelters - Four U.S. Cities, March 27-April 15, 2020. MMWR Morb Mortal Wkly Rep. 2020;69(17):521-522. Published 2020 May 1. https://doi.org/10.15585/mmwr.mm6917e1

9. Tobolowsky FA, Gonzales E, Self JL, et al. COVID-19 Outbreak Among Three Affiliated Homeless Service Sites - King County, Washington, 2020. MMWR Morb Mortal Wkly Rep. 2020;69(17):523-526. Published 2020 May 1. https://doi.org/10.15585/mmwr.mm6917e2

10. Bodkin C, Mokashi V, Beal K, et al. Pandemic Planning in Homeless Shelters: A pilot study of a COVID-19 testing and support program to mitigate the risk of COVID-19 outbreaks in congregate settings [published online ahead of print, 2020 Jun 8]. Clin Infect Dis. 2020;ciaa743. https://doi.org/10.1093/cid/ciaa743

11. Kumar Kar S, Arafat SMY, Marthoenis M, Kabir R. Homeless mentally ill people and COVID-19 pandemic: The two-way sword for LMICs. Asian J Psychiatr. 2020;51:102067. https://doi. org/10.1016/j.ajp.2020.102067

12. Chau S, Chin M, Chang J, et al. Cancer risk behaviors and screening rates among homeless 
adults in Los Angeles County. Cancer Epidemiol Biomarkers Prev. 2002;11(5):431-438

13. Long HL, Tulsky JP, Chambers DB, et al. Cancer screening in homeless women: attitudes and behaviors. J Health Care Poor Underserved. 1998;9(3):276-292. https://doi.org/10.1353/ hpu.2010.0070

14. Desai MM, Rosenheck RA. HIV testing and receipt of test results among homeless persons with serious mental illness. Am J Psychiatry. 2004;161(12):2287-2294. https://doi.org/10.1176/ appi.ajp.161.12.2287

15. Kirby T. Efforts escalate to protect homeless people from COVID-19 in UK. Lancet Respir Med. 2020;8(5):447-449. https://doi.org/10.1016/s2213$2600(20) 30160-0$

16. Leung CS, Ho MM, Kiss A, Gundlapalli AV, Hwang SW. Homelessness and the response to emerging infectious disease outbreaks: lessons from SARS. J Urban Health. 2008;85(3):402-410. https://doi.org/10.1007/s11524-008-9270-2

17. Tsai J, Rosenheck RA. Religiosity among adults who are chronically homeless: association with clinical and psychosocial outcomes. Psychiatr Serv. 2011;62(10):1222-1224. https://doi. org/10.1176/ps.62.10.pss6210 1222

18. IBM Corp. IBM SPSS Statistics for Windows, Version 24.0. Armonk, NY: IBM Corp; 2016.

19. HUD 2019 Continuum of Care Homeless Assistance Programs Homeless Populations and Subpopulations, Florida. US Department of Housing and Urban Development. https://files. hudexchange.info/reports/published/CoC PopSub State FL 2019.pdf. Published January 27, 2019. Accessed August 17, 2020.

20. Kohlberg, Lawrence; Charles Levine; Alexandra Hewer. Moral stages: a 266 current formulation and a response to critics. Basel, NY: Karger; 1983.

21. Kong KL, Chu S, Giles ML. Factors influencing the uptake of influenza vaccine vary among different groups in the hard-to-reach population. Aust N Z J Public Health. 2020;44(2):163-168. https://doi.org/10.1111/1753-6405.12964 